Original Research Paper

\title{
A Note on the Marine Policy of the Ferry Sewol-Ho Disaster in Korea
}

\author{
${ }^{1}$ Joung Keun Cho and ${ }^{2}$ Seok Yoon \\ ${ }^{I}$ Graduate School of Business Administration, \\ Seokyeong University, 16-1 Jungneung-Dong, Sungbuk-Ku, Seoul 136-704, Korea \\ ${ }^{2}$ College of International Business, Division of Business Administration and Economics, \\ Konkuk University, 322 Danwol-Dong, Chungju-Si, Chungcheonbuk-Do, 380-701, Korea
}

\author{
Article history \\ Received: 18-11-2014 \\ Revised: 19-12-2014 \\ Accepted: 24-01-2015 \\ Corresponding Author: \\ Joung Keun Cho \\ Graduate School of \\ Business Administration, \\ Seokyeong University, 16-1 \\ Jungneung-Dong, Sungbuk- \\ $\mathrm{Ku}$, Seoul 136-704, Korea \\ Email: johncho@alumni.cmu.edu
}

\begin{abstract}
The passenger ship Sewol-ho traveling from the port of Incheon to Jeju island tragically capsized and sank off west coast of Jindo island in April of 2014. Of 476 passengers and crew on board the ship, just 172 were rescued and 294 are confirmed dead while 10 bodies remain missing. The tragedy is man made and unparalleled in modern Korean history. Due to such a large-scale disaster, South Korea's marine and shipping policies are phasing into a critical turning point where policies for South Korea's marine, shipping and vessels should be focused on substantially supplementing and strengthening disaster countermeasures, safety facilities and safety standards. Therefore, this study diagnoses the cause of damage, present status and issues caused by Sewol-ho disaster, as well as suggests policy improvements the government should drastically work on. Related amendments to law were presented as part of the measures, while establishing the special Sewol Law expected to improve total incompetence is also under discussion. However, the National Assembly has made very slow progress in discussing this. What is more important is to determine who should be responsible, while setting up policies for the following at the earliest moment: Taking preventive measures against reoccurrence in every aspect, preparing for maritime disasters and reinforcing safety standards. Otherwise, there is no bright future for us.
\end{abstract}

Keywords: Maritime Disaster, Ferry Disaster, Marine Accident, Sinking Accident, Matine Policy

\section{Introduction}

The ferry Sewol (hereinafter Sewol-ho) traveling from the port of Incheon to Jeju island was reported to be sinking around 08:58 on April 16, 2014. Then, Sewolho capsized around 10:31 on the nearby sea about 1.4 nautical miles (about $2.5 \mathrm{~km}$ ) near Donggaecha island and finally sank. The sinking of Sewol-ho, briefly speaking, refers to the accident where a passenger ship carrying high school students on a school trip to Jeju island capsized of the cost of Jindo island while heading to the resort island. At the time of the accident, Sewol-ho had 476 passengers on board and loaded 2,142 tons of cargo including vehicles. Of the passengers on board, tourists were 433 and crew members were 33 , some 350 of those were high school students and teachers, with 104 ordinary passengers counted.

Of the 476 passengers and crew on board, only 172 people were rescued in this maritime disaster. The tragedy is one of the worst maritime disasters in the country's history, leaving 294 dead and 10 still missing. MPA 2014 this large-scale disaster is the biggest accident among all man-made accident records, major enough probably to be recorded even in world war history.

South Korea has aimed to become a maritime power just until such a mega maritime disaster took place. It was everyone's understanding that the country takes the world's top and second position in shipbuilding tonnage, taking the lead in maritime cargo as well and maritime employees and research activities were on right track. South Korea's maritime, shipping and shipbuilding face a significant crisis due to this disaster. Briefly speaking, South Korea's marine and shipping policies are phasing into a critical turning point where disaster measures, safety facilities and safety standards need to be substantially reinforced.

Thereby, this study is intended to provide an insight into causes, damage status and preventive measures against reoccurrence in regard to the sinking accident Sewol-ho Disaster in the southern sea off Jindo island in South Korea. The additional purpose of this study is to 
look back at the importance of marine safety by taking it as the lesson of history in preventing the recurrence of such a disaster and to look into policy alternatives to overcoming such a crisis by enhancing the competitiveness of the maritime sector.

\section{Causes of the Disaster and Conditions of Damage}

\section{Cause of Sinking}

Despite multiple investigations into the cause of the accident based on the time when the accident took place, the cause of the ferry's sinking has not been identified yet. No apparent performance has not come out though administrative investigation and criminal investigation are separated, while police and prosecutors and government officials in responsible ministries and other agencies are busy handling the accident and conducting search and rescue operations.

The joint investigation of police and prosecutors conducted so far as to the cause of the accident has revealed results. Firstly, the ship capsized while creating an outside slope which is formed in the opposite of the hull making a turn. Secondly, overloaded cargo and poor fastening of the cargo. Thirdly, failure in loading specified ballast water, with an extremely poor hull stability due to overloading and lack of ballast water. Fourthly, failure to follow any of obligatory shipping crew conduct codes according to safe ship management regulations, such as action guidelines in the event of casualties and on-board emergency drills and training on a regular basis.

\section{Details of Accident}

The passenger ship Sewol-ho that travels from Incheon city to Jeju island postponed its schedule due to bad weather conditions. But, the decision was finally made to operate the ship and the captain changed the initial course to one closer to the destination before starting the ship. Sewol-ho sank after a distress call was received for the capsizing of the ferry in the neighboring sea 3.1 nautical miles (about $5.6 \mathrm{~km}$ ) northeast of Jindo island county. The left side of the hull began to capsize and it took just ninety minutes for the ferry to completely sink. Figure 1 shows the sea accident map.

\section{Damage Status (As of June 29, 2014)}

Damages from Sewol-ho accident include damage to humans, property damage and other marine pollution damage. Firstly, as for damage to humans, 172 people out of 476 passengers were rescued and 294 people confirmed dead, with 10 people still missing. Of the victims, 250 bodies were recovered from inside the ship and 43 bodies from outside (KMOF, 2014a). Most of all, among the victims, there were 245 students, 9 teachers,
34 ordinary passengers and 5 crew members. Even 100 days after the disaster, 10 people ( 5 students, 2 teachers and 3 ordinary passengers) are still missing to everyone's great disappointment (ME, 2014). Table 1 shows detailed damage to humans.

Secondly, the hull of Sewol-ho and the entire cargo load completely capsized about 40-48 m underwater. Property damage caused by this came to 2,142 tons of cargo, which includes vehicles weighing 552 tons, 320 tons of cargo vehicle and 1,270 tons of container. The ship capsized with the port of the hull in contact with the ocean floor. Therefore, all cargo loaded is included in the damage and vehicle fuel loaded in the cargo and container freight all come under property damage.

Thirdly, when it comes to maritime pollution and damages to local residents, the oil leaked from Sewol-ho flew into the neighboring fish farms and coasts of Donggeocha island. The leaked oil was removed through the clean-up project, but how to deal with remaining oil is at issue and there is a possibility that the oil leakage connects to primary and secondary damage. On top of this, damage compensation is currently under way with affected local residents who suffered from damage or closure to their place of life, fish farms and other issues forcing them out of work.

\section{Rescue Status and Searching for Missing Persons}

Sewol-ho disaster can be referred to as a stereotypical man-made accident. Alleged poor search and rescue operations following the ferry accident make people grow more anxious though it was difficult to keep the accident from occurring beforehand. In other words, there was a lack of proper rescue efforts to save lives in Sewol-ho disaster, where a person died dumpfoundly in the course of excessive search effort for missing persons.

When the sinking accident occurred, the government of South Korea established the Disaster Countermeasures Headquarters and declared the ferry sinking site as a special disaster zone and took priority measures necessary to save lives. The government also set up the accident recovery system for missing persons and the dead and coped with the accident at early stage. What mattered most was making up a response team at the scene of accident as well as a public-private partnership system. In addition to this, it established diversified support systems for both rescuers and those injured, such as emergency medical services, psychological support and funeral services for victims (MHW, 2014).

In particular, the country's government is making various search and rescue efforts for missing persons, along with maritime search, underwater search and aircraft search for preventing missing persons from being lost, in view of weather conditions, tide current and wave heights in nearby costal areas including island regions. 


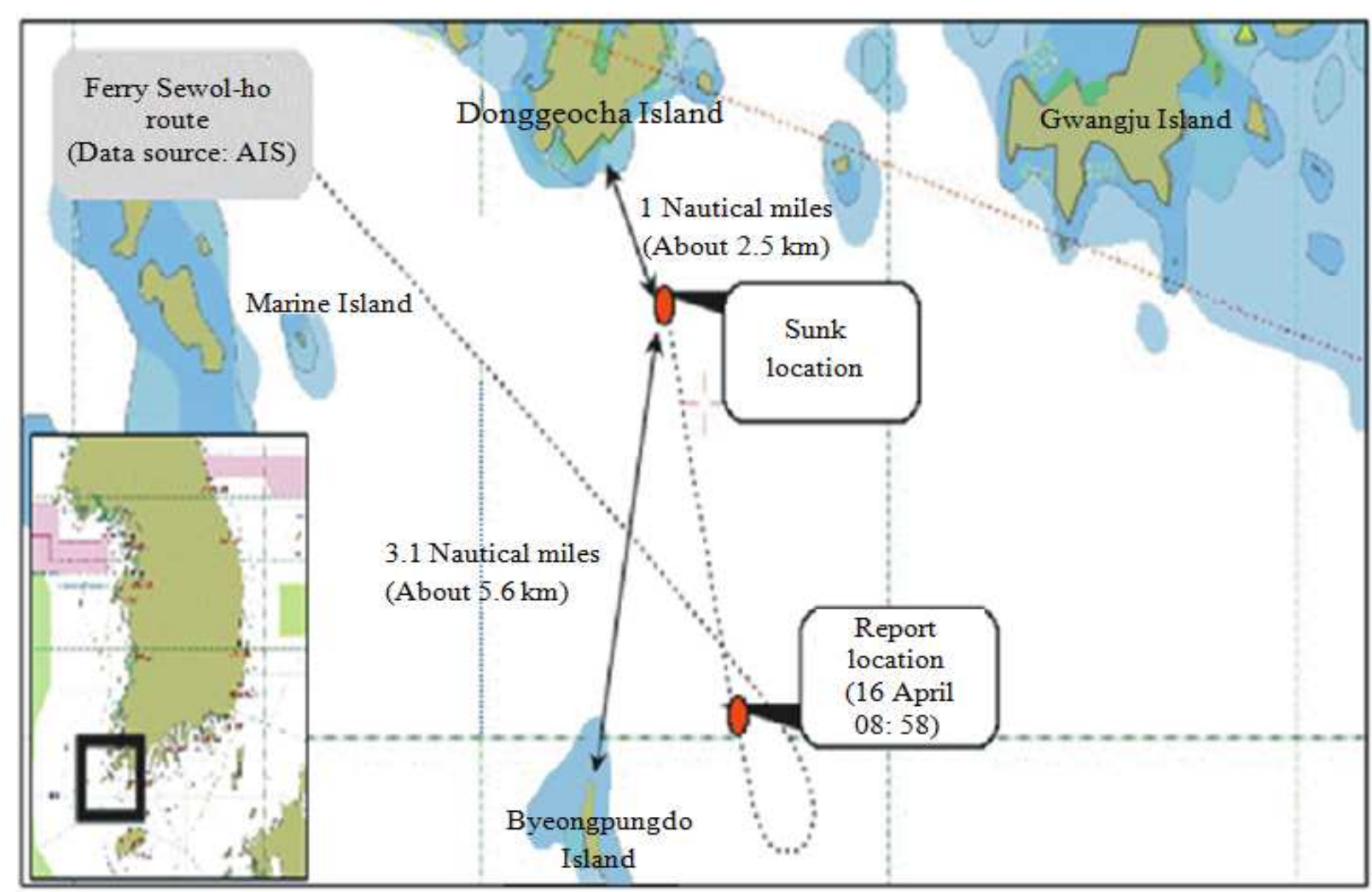

Fig. 1. Sea accident map Source: National maritime police, July 2014

Table 1. Detailed damage to humans (Unit: Person)

\begin{tabular}{lcccccc}
\hline Classification & Total & Student & Teacher & Ordinary passenger & Crew member & Others \\
\hline Passenger on board & 476 & 325 & 14 & 104 & 23 & 18 \\
Survivor & 172 & 75 & 3 & 71 & 5 & 5 \\
Victim & 294 & 245 & 9 & 30 & - & 5 \\
Missing person & 10 & 5 & 2 & 3 & - \\
\hline
\end{tabular}

Source: Korea ministry of oceans and fisheries, July 2014

\section{Total Incompetence and Issues}

Supposing that South Korea is, in short, a car adopting capitalistic market economy, unfortunately its control system is completely useless. A car with a faulty control system has no choice but to get involved in frequent accidents in many ways. This undoubtedly makes people insensitive to safety while putting them to live in the absence of social system that neither works nor inter-communicates.

The issue this ferry Sewol disaster faces indicates it reveals collective South Korea's incompetence. There have been numerous problems even before this disaster happened and on the day of the accident, the government officials focused overly on regulations, passed responsibility on to others and had no idea what their duties were. This put them in the midst of confusion, which led to a poor initial response to the disaster and hampering research and rescue efforts, finally turning to police and prosecutors for its investigation.

Public Administration's incompetence comes in many aspects even following the disaster, such as a search and rescue issue, damage issue, compensation issue, issue for various support programs and an insufficient function of a control tower for taking measures between government ministries (OGPC, 2014). This study aims to deal primarily with pending issues that came up on the day of accident and after the accident, prior to the sinking accident (http://bbs1.agora.media.daum.net/gaia/do/debate/ read?bbsId=D003andar ticleId=5209883).

\section{Until the Last Minute of Sinking Accident}

- Who should be held responsible for passing the bill to extend the lifespan of the 20-year-old ferry Sewol up to 30 years? 
- Were there any illegal or fraudulent transactions involved in the process of purchasing the than-18 year old ferry Sewol at bargain prices, modifying and using it as a passenger ship? (The ferry was confirmed to fundamentally have insufficient ballast in the modification process)

- The capsized ferry was modified to accommodate more passengers. Is the Korean Register of Shipping free from responsibility for issuing an approval knowing the modification could affect ship functionality and advising the company to load cargo less? (Sewol-ho was actually confirmed to have carried more than three times its recommended maximum cargo limit)

- Sewol-ho had many technical problems caused by engine or screw failure even before the accident, but Chonghaejin Marine Co., Ltd did not take proper action. Therefore, it is questionable that how Sewol-ho passed the regular safety checkup and operated normally

- Did maritime police follow the search and rescue manual on the day of accident during the rescue operation? Do they keep a related manual handy? If they have, how much time did they spend annually performing related training and drills?

- Is the Ministry of Security and Public Administration ready to set up and operate an accident recovery system under the organic, systematic control in selecting authorized personnel and coordinating the internal system with outside source, in the face of an accident equivalent to a national disaster? (Minister of Security and Public Administration resigned over the ferry disaster)

\section{On the Day of Sinking Accident}

- What responsibility should be laid on the shipping company involved in cargo overloading and the negligence of management and supervision?

- Was the freight inside the ship fastened as per regulations?

- Did the captain and crew members make utmost efforts to help evacuate the passengers when they noticed the ship sinking looked inevitable

- Jindo Vessel Traffic Services knew Sewol-ho entered its jurisdiction but did not make any report of it. Then, did the authority notice this?

- Is it appropriate to ask the student caller, on the verge of the sinking, about the latitude and longitude on the map instead of the name of the ship? Were those questions made according to the instruction manual?

- Did Jindo Vessel Traffic Services know Sewol-ho stayed in its jurisdiction until it was stranded there?

- It was confirmed that the captain and crew escaped the sinking ship shortly after the accident, without considering passenger safety. How come is this possible?

\section{After the Sinking Accident}

- Is it certain that the Ministry of Security and Public Administration, military forces, coast guard and civilians performed search and rescue operations on the effective and integrated system? If not, what made them unable to complete it and who should be responsible for it?

- Is it appropriate under the circumstances for the company which caused the tragic accident to make a contract with a private rescue operation company whose personnel were sent to the accident site for rescue work?

- What responsibility should the media and broadcasters take for releasing articles different from what is actually happening on the scene?

- Who should be held responsible for the happening witnessed in the process of deploying a technologically advanced diving bell in a timepressed situation for saving lives?

- Who should be held responsible for failing to properly perform the special parliamentary probe into the ferry disaster at the National Assembly. Furthermore, who should be also responsible for the absence of legislation where various legislation amendment bills are drifting along?

As examined earlier, there have been many problems in several aspects even before the sinking accident took place. Even after the tragic accident occurred, the field officials or authorities showed the negligence of crisis management. Some politicians in the ruling and opposition parties, in the meantime, made apologies for their comments during/after their visit to the scene of the disaster and got involved in certain happenings. General problems were pointed out, such as spreading all sorts of false rumors online in the process of handling the ferry accident or providing support, parachute-style appointment led by the government and a lack of government crisis management capabilities.

It should be understood that those previouslymentioned problematic facts are accepted in Korean society. Each and everyone of us living in such a society should embrace the problems and take responsibility for them, excepting nobody.

\section{Materials and Methods}

This study made reference to previous results and various documents with a focus on countermeasures 
taken by related ministries and present status following the Sewol-ho disaster. In addition, the objective of this study is to complete ultimate measures and complementary measures of related systems with the use of documents on ripple effects of government announcements regarding disaster victims and families and student academic issues.

In other words, this study deals with establishing Sewol-ho related legislation, investigating its cause and measures, making up for causes and issues based on government's policy alternatives with respect to damage compensation and presenting fundamental policies and institutional supplementary tasks for Sewol-ho disaster.

\section{Support Measures for Damage Compensation}

On April 20, 2014, the government declared the city of Ansan and Jindo County affected by the accident as special disaster zones to deal promptly with damage compensation as Sewol-ho accident took place. This was conducted in order to facilitate prompt accident recovery and various support measures for victims, families and damaged areas (KMOF, 2014b). Most of all, it made up the damage compensation support team for a systematic response and assistance.

Considering a prolonged damage compensation, the government helps implement compensation procedures including a systematic inspection into damage details by type, a discussion with the family members of victims and damage assessment. Figure 2 shows the procedures for damage compensation. It also provides supports for Sewol-ho-related special law, a basis for the damage compensation, to be established at the earliest moment.

\section{Livelihood Support and Medical Aid}

The prolonged ferry Sewol accident has caused several side effects from damage. The most important of all includes medical aid to those injured and financial difficulties arising out of concerns over livelihood of the families of victims.

Firstly, it was decided that rescuers and victim's families would receive medical services, such as first aid treatment, psychological counseling and back-toschool programs. The following supports are available until the end of the year (Separate period of time for psychological treatment): Support for hospital treatment charges, support for post-traumatic stress disorder and psychological counseling support for students, teachers and parents.

Secondly, emergency fund for livelihood recovery are supported to ease financial difficulties. According to the decision made for support of livelihood recovery fund to the families of victims, missing persons and injured people (per household), about 1 billion Won (27 June) was distributed to 455 applicants out of 461 people entitled to receive payments, as livelihood recovery fund (per household) of 850,000 Won, 420,000 Won for relief fund (per person) and 700,000 Won for loans for high school students (per person) (IMC, 2014).

To help relieve the difficulties arising out of falling income due to long-term business shutdown and career at risk owing to taking many days off from work, a decision came out to provide 1.2 million Won as support for a leave of absence and business shutdown. To reduce the financial burden of the families of victims, the following are in effect: An extension of payment due date, reduction and exemption for taxations (national tax, local tax), health insurance payments and pension (MEL, 2014a).

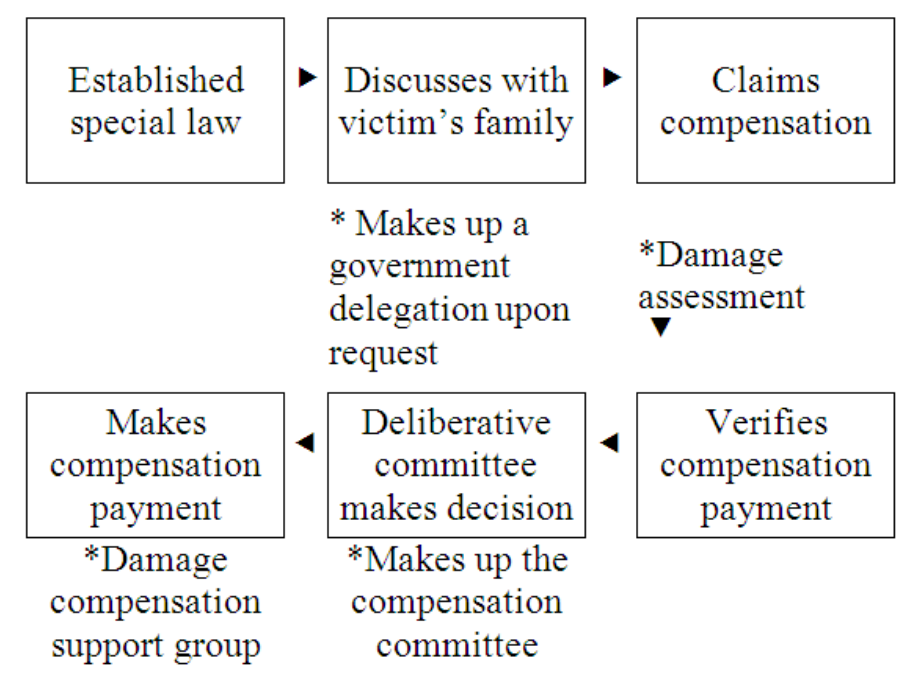

Fig. 2. Compensation process flowchart Source: Korea ministry of oceans and fisheries, July 2014 


\section{Support for Residents in Affected Areas}

For the sake of the areas and residents affected by Sewol-ho accident, comprehensive government measures for economic recovery in Jindo island and Ansan areas are in progress by inter-ministry cooperation. This is especially focused on setting the ground for vitalizing the local economy in Jindo island and Ansan.

Firstly, fishing boats called up for search and rescue operation receive actual expenses and coverage for operating loss, whereas fishing boats voluntarily participating in the rescue work receive actual expenses. Besides, each family of the fishermen in intensive search and rescue areas who were affected by the ferry accident receive 850,000 Won as a compensation for their limited fishing activities (MEL, 2014b).

Secondly, now that the prolonged search operation for missing persons has led to slows sales of local fishery products and reduction in visitors, financial projects in the fishery sector will receive support which is considered to be reflected in 2015 Business Budget (Plan) for Jindo County.

\section{Future Accident Recovery and Preventive Measures Against Reoccurrence}

Government's policy and direction regarding the sinking accident of Sewol-ho should go in a way that helps the families of victims and rescuers overcome the hardships and go back to their routine. That is, they should unite all their utmost efforts to help bring psychological, mental and economic distress caused by Sewol-ho disaster back to the normal state of stability. This should be established on the condition that national disaster and safety system putting people's safety on top priority be set up, while reflecting upon Sewol-ho tragedy.

As an alternative to this, a number of law amendments in regard to rescue and support programs for Sewol-ho's sinking accident are presented to the National Assembly as well. A move to establish so called the special Sewol Law is in progress. The law includes everything from rescue operations in Sewolho accident to support for victim's families and compensation, compensation for affected areas and safety and management measures concerning the ocean, shipping and vessels. Following policies should be discussed and complemented as concrete policy alternatives to this.

\section{Search and Rescue Operations and Preventive Measure against Loss}

Searching for missing persons is the top priority in accident recovery process. The maritime police should bring more effective ways of search activities, putting focus on suspected areas where missing persons may remain, while completely guaranteeing diver's safety and fully providing necessary resources. An in-depth search should consider weather conditions and tidal currents and prepare for the rainy season and typhoons on a long-term basis.

The completed area of search should be put on video and the search operation should also be more focused through identification from the families of missing persons and the verification team. On top of this, opinions from the field command post, divers and experts should be continually collected, while reviewing alternatives applicable both home and abroad in the open mindset to put them promptly in actual situations. For preventive measures against the loss of missing persons, continual aircraft and maritime search activities are needed, small fishing boats should be called up for hardto-reach areas, such as cliffs and caves and setting up a vessel for loss prevention is urgent.

\section{Measures for Coastal Passenger Ship Safety Management}

Thorough improvement should be carried out on safety management system and lack of vessel safety which were indicated as direct and indirect cause of Sewol-ho tragedy. As well, reasonable and proper safety standards and regulations of law should be prepared and complemented to prevent a similar accident from recurring. So far, the private-public joint $\mathrm{T} / \mathrm{F}$ involving the participation of international register of shipping and research institutions was established and operated and innovative measures for coastal passenger ship safety management was prepared through the discussion among related ministries. The final draft is scheduled to be made in light of future discussions of Special Committee on National Probe of the National Assembly.

Details of these innovative measures are as follows: Firstly, vessel management is separated from the maritime union, with the introduction of a computerized ticketing system, so that the government has direct management over the passenger ship management through the marine safety inspector. Therefore, the measures are expected to stop overloaded cargo and make cargo insurance obligatory through what is needed for vessel management, such as computerized ticketing for users (computerized input of personal information), the reinforcement of identify verification process and the introduction of computerized cargo ticketing system.

Secondly, it involves strict management of the introduction of second-hand ships and excessive modification. That is, the car ferry is 20 years old, in principle, extendable up to 5 years on the condition that it receives a reinforced annual inspection for a 
vessel life extension. Government's vessel inspection agentship is open to the foreign agency (based on the principle of reciprocity), sharing the license issuing authorities of inspection information (cargo, amount of ballast water, maximum capacity and operational conditions). When it comes to modifying a vessel, a passenger ship with poor stability is prohibited from being modified, economic vessel operation is considered, a regular inspection is conducted to see if life-saving equipment properly works and special inspection is supposed to be performed on a maintenance enter when the equipment does not work.

Thirdly, this involves improvement of education and training and working conditions to strengthen a sense of mission of crew members, whose responsibilities are enhanced by setting standards for captains and crew of large-scale passenger ships higher (from second officer to chief officer), strengthening aptitude tests for a captain, making the wearing of uniforms obligatory and enhancing education (i.e., a sense of mission). It also includes carrying out on-board emergency training and putting 'passenger-dedicated crew members' on board for guidelines for passenger safety education to increase emergency response capabilities.

Fourthly, there will be strengthened punishments and support systems prepared to improve the safety management of shipping companies. It will be obligatory to hire people solely responsible for the safety management of shipping companies and when failing to fulfilling safety obligations, punishments are substantially strengthened.

\section{Public-Private Relationship Reestablishment}

The government points out wrong practice caused by the collusion between marine industry and inspection agencies as one of the direct causes of the sinking disaster. Thereby, the government and private sectors need to share roles, reestablishing their relationship as well.

To redefine such a relationship, first of all, strengthened measures should be taken to prevent and control the corruption of subsidiary public organs and related organizations and thoroughly fulfill fundamental ways for improvement, after all. Sectors vulnerable to corruption will be found out and inspection will be mainly focused on prevention activities, to prevent money, entertainment and convenience from being conventionally provided. Punishment levels are raised if the corruption is caught. To improve the discipline of public officials and the degree of integrity, subsidiary agencies are entitled to independently set up plans to manage public services suited for their own features, strengthening independent inspection activities.
Second of all, there is a need to improve the practice of rehiring retired public employees in affiliated organization. That is, thorough management for retirees is required. For example, when a retired public employee found a job in agencies under regulation and safety sectors and public companies, the person should be encouraged to quit the job voluntarily at the earliest possible moment. Agencies and public companies in the service sector, on the other hand, are recommended to recruit competent private professionals as the heads of agencies and inspectors, in consideration of the nature of work.

In particular, when it comes to rehiring public employees, it is required to actively carry out the reinforced measures Revision of Public Service Ethics Act-in progress at the government-wide level-for restricting them from being rehired in governmentrelated organizations.

\section{Results}

The findings of this study are listed below. Firstly, measures to build national disaster management system prioritizing people's safety should be taken while reflecting on Sewol-ho disaster. Secondly, it is urgent to establish what we call Special Sewol Law that covers all things from rescue operation in Sewolho disaster, support and compensation for the families of victims, compensation for damaged areas and to comprehensive safety measures related to marine, shipping and vessel.

\section{Discussion}

The ruling and opposition parties have different viewpoints regarding the "special Sewol Law" submitted to the National Assembly and there is a prevailing evaluation that opinions of Sewol victims' families were not sufficiently reflected. Such matters pointed out should be discussed in the National Assembly. Safety standards should be established to keep no similar disaster to Sewol-ho from happening, along with sufficient compensations for the affected people by the disaster. If this fails, the government also will face distrust amongst its people and political parties will not be immune to such responsibility.

\section{Conclusion}

We occasionally visit the sea when feeling gloomy. When exposed to the open-sea view, we find ourselves forgetting about the stuffy routine without knowing. Not so long ago the sea off the coast of Jindo island was one of those seas. But, now the sea is filled with such wailing and tears that it gives each of us grief, despair and distress. This change is what Sewol-ho disaster brought to us. 
This is the second time to say that Sewol-ho sinking accident is a man-made disaster. Therefore, those involved in the disaster should be held responsible and subsequent punishments should undoubtedly follow. It is too late to identify who was right and wrong and who was to blame, in such an accident. In other words, it is like shutting the stable door after the horse is stolen. It is a peripheral issue to punish those in charge. Basically, laws and systems should be established to detect such an accident beforehand and prevent it. The operation and enforcement of such laws should be strict like the very edge of a knife. There is no way to bring the justice and for peace to sets in, if anyone thinks 'I can be an exception.' and if any form of injustice which accepts the thought is compromised.

As examined earlier, sufficient discussion, modification and supplement should be done in regard to issues indicated as the problems in Sewol-ho tragedy caused by the indifference to safety between the marine industry and inspection agencies and between the government and private sectors, as well as policy alternatives considered as measures for improvement. These are not optional but essential. Our objective is to raise the quality of life by pursuing happiness and secure the competitiveness of the maritime sector, as well. To meet the two objectives, the advanced system should be established through thorough reform and its accommodation.

Conclusively speaking, someone's life is really precious above all and efforts to keep the life alive should be on top value. Society thriving on this belief is a happy and healthy society. Society going in opposite direction, on the other hand, has no future and is unable to create a value for human respect. All our society members should work together to prevent an accident that looks like shutting the stable door after the horse is stolen. We have no future if we keep on like this.

\section{Acknowledgement}

This research was supported by Konkuk University and Seokyeong University research program.

\section{Funding Information}

This research was supported by Konkuk University and Seokyeong University research grants in 2013.

\section{Author's Contributions}

Joung Keun Cho: Collecting the basic data source from an accident area, conducting survey and manuscript writing from the source.
Seok Yoon: Designing the research plan, orgnazing the study, coordinating the data analysis as well as the government policy debates and suggesting alternatives.

\section{Ethics}

We hereby testify that this material has not been published in whole or in part elsewhere. The Manuscript is not currently being considered for publication in another journal. All authors have been personally and actively involved in substantive work leading to the manuscript and will hold themselves jointly and individually responsible for the originality of its contents.

\section{References}

http://bbs1.agora.media.daum.net/gaia/do/debate/ read?bbsId=D003andar ticleId $=5209883$

IMC, 2014. Support of livelihood recovery fund to the families of victims in Sewol-ho sinking accident. Press release.

KMOF, 2014a. Status of Sewol-ho accident recovery. Korea Ministry of Oceans and Fisheries.

KMOF, 2014b. Progress on and follow-up measures for Sewol-ho accident recovery. Special Committee of Parliamentary Investigation in the National Assembly.

ME, 2014. Progress on and follow-up actions for Sewol-ho accident recovery. Special Committee of Parliamentary Investigation in the National Assembly.

MEL, 2014a. Special assistance for the families of Sewol-ho accident victims. Special assistance for sustenance of employment. Press release.

MEL, 2014b. Reports on the ferry Sewol-ho sinking accident. Special Committee of Parliamentary Investigation in the National Assembly.

MHW, 2014. Measures for handling Sewol-ho sinking accident and future plans. Special Committee of Parliamentary Investigation in the National Assembly.

MPA, 2014. Sewol-ho sinking accident. Special Committee of Parliamentary Investigation in the National Assembly.

OGPC, 2014. Reports on the ferry Sewol sinking accident. Special Committee of Parliamentary Investigation in the National Assembly. 